\title{
Estimation of renal function by CKD-EPI versus MDRD in a cohort of HIV-infected patients: a cross-sectional analysis
}

\author{
M. P. Cristelli ${ }^{1 \dagger}$, F. Cofán ${ }^{2 \dagger}$, N. Rico ${ }^{3}$, J. C. Trullàs ${ }^{4,5}$, C. Manzardo ${ }^{6}$, F. Agüero ${ }^{6}$, J. L. Bedini ${ }^{3}$, A. Moreno $^{6}$, \\ F. Oppenheimer ${ }^{2}$, J. M. Miro ${ }^{6^{*}}$ and the CKD-H. Clinic Investigators
}

\begin{abstract}
Background: Accurately determining renal function is essential for clinical management of HIV patients. Classically, it has been evaluated by estimating glomerular filtration rate (eGFR) with the MDRD-equation, but today there is evidence that the new Chronic Kidney Disease Epidemiology Collaboration (CKD-EPI) equation has greater diagnostic accuracy. To date, however, little information exists on patients with HIV-infection. This study aimed to evaluate eGFR by CKD-EPI vs. MDRD equations and to stratify renal function according to KDIGO guidelines.

Methods: Cross-sectional, single center study including adult patients with HIV-infection.

Results: Four thousand five hundred three patients with HIV-infection (864 women; 19\%) were examined. Median age was 45 years (IQR 37-52), and median baseline creatinine was $0.93 \mathrm{mg} / \mathrm{dL}$ (IQR 0.82-1.05). A similar distribution of absolute measures of eGFR was found using both formulas ( $p=0.548$ ). Baseline median eGFR was 95.2 and $90.4 \mathrm{~mL} / \mathrm{min} /$ $1.73 \mathrm{~m}^{2}$ for CKD-EPI and MDRD equations ( $p<0.001$ ), respectively. Of the 4503 measurements, 4109 (91.2\%) agreed, with a kappa index of 0.803 . MDRD classified $7.3 \%$ of patients as "mild reduced GFR" who were classified as "normal function" with CKD-EPI. Using CKD-EPI, it was possible to identify "normal function" (>90 mL/min/1.73 $\left.\mathrm{m}^{2}\right)$ in $73 \%$ patients and "mild reduced GFR" (60-89 mL/min/1.73 $\left.\mathrm{m}^{2}\right)$ in $24.3 \%$ of the patients, formerly classified as $>60 \mathrm{~mL} / \mathrm{min} / 1.73 \mathrm{~m}^{2}$ with MDRD.

Conclusions: There was good correlation between CKD-EPI and MDRD. Estimating renal function using CKD-EPI equation allowed better staging of renal function and should be considered the method of choice. CKD-EPI identified a significant proportion of patients (24\%) with mild reduced GFR (60-89 mL/min/1.73 m²).
\end{abstract}

Keywords: HIV-infection, Chronic kidney disease, Glomerular filtration rate estimates

\section{Background}

Chronic kidney diseases (CKD) have become one of the leading causes of mortality among patients with HIV infection, and are often associated with comorbidities that affect kidney function, such as diabetes mellitus and hypertension [1-4]. The reported prevalence of renal diseases ranges from 3 to $24 \%$ [4-8], depending on the definition of renal disease, study population, and access to health services. Furthermore, although the widespread

\footnotetext{
*Correspondence: jmmiro@ub.edu

${ }^{\dagger}$ Equal contributors

${ }^{6}$ Infectious Diseases Service, Hospital Clinic - IDIBAPS, University of Barcelona, Barcelona, Spain

Full list of author information is available at the end of the article
}

use of antiretroviral therapy (ARV) has decreased the incidence of HIV-associated nephropathy, the overall prevalence of renal disease continues to increase among people living with HIV [9].

An accurate assessment of renal function in the HIVinfected population is essential, because HIV treatment with ARV involves complex drug regimens often accompanied by significant side effects and drug interactions. A significant number of these drugs undergo renal elimination and demand dose-adjustments according to kidney function [10].

Methods based on the clearance of exogenous markers, like inulin, ${ }^{51} \mathrm{Cr}$-EDTA and iohexol, are the gold standard for glomerular filtration rate (GFR) measurement, but are 
cumbersome and infrequently used in clinical settings [11]. Numerous equations used to estimate creatinine clearance or GFR have been used over the past few decades. Two of the most commonly used equations (Cockroft-Gault [CG] and Modification of Diet in Renal Disease [MDRD]) are derived from persons with GFR $\leq 90 \mathrm{~mL} / \mathrm{min} / 1.73 \mathrm{~m}^{2}$, have not been validated among persons with normal kidney function, and tend to underestimate higher GFRs [12]. Meanwhile, the CKD-EPI (CKD Epidemiology Collaboration) equation has been evaluated in several populations and become the most accurate GFR estimating equation [13-15]. Recently, the CKDEPI equation has been recommended as the first-choice method to assess renal function by the 2016 European AIDS Clinical Society (EACS) Guidelines [16].

This study aimed to analyze eGFR in a large cohort of patients with HIV infection followed-up in a single center and to evaluate the renal function estimation obtained by the CKD-EPI versus the MDRD equation, also stratifying patients according to different degrees of chronic kidney disease.

\section{Methods}

This was an observational, cross-sectional, retrospective, single center study. The study project was reviewed and approved by the Institutional Review Board (CEIC Hospital Clinic i Provincial, Barcelona, Spain, IRB\# 2014/1080). Eligible patients were all adult HIV-1infected patients ( $>18$ years old) with at least one routine visit during the calendar year of 2014. Patients were excluded if they had not had at least two measurements of serum creatinine during the year 2014 and/or if they had had a diagnosis of end stage renal disease, dialysis and/or transplantation before the diagnosis of HIV infection. Patients were considered as having hypertension, diabetes and/or dyslipidemia if they were receiving specific treatment for these conditions.

All available serum creatinine values were obtained from the hospital electronic patient record system and were converted into eGFR, using age, gender and the CKD-EPI and MDRD equations. We did not consider the African-American coefficient factor as applicable to black patients from Africa, Europe and the Antilles [17], because this information is not available in the electronic medical records, although the prevalence of black patients in our institution, regardless their HIV-status, is very low $(<3 \%)$.

Impaired renal function (eGFR $<90 \mathrm{~mL} / \mathrm{min} / 1.73 \mathrm{~m}^{2}$ ) was confirmed with a second measurement at least 3 months apart from the first "baseline" creatinine. We used clinical guidelines from the US National Kidney Foundation's Kidney Disease Outcome Quality Initiative (K/DOQI) to grade renal impairment [18]. In this study,
eGFR below $60 \mathrm{~mL} / \mathrm{min} / 1.73 \mathrm{~m}^{2}$ was used as the cutoff point for chronic kidney disease (CKD).

Statistical analyses were performed using the Predictive Analytics Software statistics for Windows, v21.0 (SPSS Inc, Chicago, IL). Normal distribution of data was assessed by the Kolmogorov-Smirnov test and data were presented as mean $( \pm \mathrm{SD})$ or as median (interquartile range) where appropriate. Categorical variables were presented as absolute frequency and percentage. When analyzing baseline eGFR, the Mann-Whitney $U$ test was used to make comparisons.

Agreement between the CKD-EPI and MDRD equations was assessed using the general linear model. The Bland and Altman method was used to estimate the global bias throughout the mean difference between GFR values and plot the differences against their means. The Kappa index was used to analyze the level of agreement between the NKF stage classifications obtained using CKD-EPI and MDRD. Statistical significance was considered if the $p$-value $<0.05$.

\section{Results}

Of the 4622 eligible patients with follow-up in 2014, 4503 were included for analysis. Excluded patients (six patients were diagnosed with end stage renal disease before HIV-infection, and the remaining 113 patients had no laboratory data in 2014) were less likely to be smokers, had a shorter duration of HIV infection (7.7 vs. 12.3 years), were less likely to be on antiretroviral treatment (91.5\% vs. 97.3\%), and had higher nadir CD4 counts and lower viral loads (data not shown).

\section{Demography}

Demographic characteristics are depicted in Table 1. Median age was 45 years [interquartile range (IQR) 37-52], median body mass index was $22.9 \mathrm{~kg} / \mathrm{m}^{2}$ (IQR 21.2-24.9), and median "baseline" creatinine was $0.93 \mathrm{mg} / \mathrm{dL}$ (IQR 0.82-1.05). Ethnicity was available for $2 / 3$ of the patients; $98 \%$ of them were non-black. History of hypertension, diabetes, and dyslipidemia was noted in 14,5 , and $13 \%$ of patients, respectively, and $5 \%$ of the patients had prior cardiovascular diseases. Median duration of HIV infection was 11 years (IQR 5-19), 20\% met the clinical definition for AIDS; 4365 patients $(97 \%)$ were receiving combined ARV, and $89 \%$ had the status of virological suppression under treatment.

\section{GFR evaluation}

Overall baseline median eGFR was $95.2 \mathrm{~mL} / \mathrm{min} / 1.73 \mathrm{~m}^{2}$ and $90.4 \mathrm{~mL} / \mathrm{min} / 1.73 \mathrm{~m}^{2}$ by the CKD-EPI and MDRD creatinine equations, respectively $(p<0.001)$.

In the absence of a gold standard method for estimating GFR, we considered two models of comparison: 
Table 1 Main demographic characteristics of 4503 patients with HIV infection included in the study

\begin{tabular}{|c|c|c|c|}
\hline Variable & Estimates & $\mathrm{n}$ & $\begin{array}{l}\text { Missing } \\
\text { information }\end{array}$ \\
\hline Median age, years (IQR) & $45(37-52)$ & 4503 & 0 \\
\hline Female sex, n (\%) & $864(19)$ & 4503 & 0 \\
\hline Black race, n (\%) & $58(2)$ & 2879 & 1624 \\
\hline Body mass index, kg/m² (IQR) & $22.9(21.2-24.9)$ & 1394 & 3109 \\
\hline Current smoker, n (\%) & $2110(51)$ & 4154 & 349 \\
\hline Hypertension, n (\%) & $619(14)$ & 4503 & 0 \\
\hline Diabetes mellitus, n (\%) & $225(5)$ & 4503 & 0 \\
\hline Dyslipidemia, n (\%) & $596(13)$ & 4503 & 0 \\
\hline Cardiovascular disease, n (\%) & $202(5)$ & 4503 & 0 \\
\hline Hepatitis B coinfection, n (\%) & $149(3)$ & 4485 & 18 \\
\hline Hepatitis C coinfection, n (\%) & $1006(22)$ & 4495 & 8 \\
\hline Mode of HIV acquisition, $\mathrm{n}(\%)^{\mathrm{a}}$ & & 4503 & 0 \\
\hline Homo/bisexual & $2650(62)$ & & \\
\hline Heterosexual & $1176(28)$ & & \\
\hline Injection drug use & $641(15)$ & & \\
\hline Other/Unknown route & $290(6)$ & & \\
\hline $\begin{array}{l}\text { Duration of HIV infection, } \\
\text { years (IQR) }\end{array}$ & $11.3(5.1-19)$ & 4478 & 25 \\
\hline Prior AIDS (yes), n (\%) & $900(20)$ & 4503 & 0 \\
\hline Current ART regimen & & 4503 & 0 \\
\hline No treatment & $138(3)$ & & \\
\hline NNRTI-based & $2381(53)$ & & \\
\hline PI-based & $144(3)$ & & \\
\hline Boosted PI-based & $1315(29)$ & & \\
\hline Integrase inhibitors-based & $493(11)$ & & \\
\hline Others & $32(1)$ & & \\
\hline Nadir CD4 cell count (IQR) & 249 (129-369) & 4484 & 19 \\
\hline Current CD4 cell count (IQR) & $628(450-830)$ & 4501 & 2 \\
\hline Current HIV infection status & & 4503 & 0 \\
\hline Suppression on Treatment & $4031(90)$ & & \\
\hline $\begin{array}{l}\text { No suppression (viral load > } \\
50 \text { copies) }\end{array}$ & $471(10)$ & & \\
\hline
\end{tabular}

$I Q R$, interquartile range; $H I V$, human immunodeficiency virus; $A I D S$, acquired immunodeficiency syndrome; NNRTI, non-nucleoside reverse transcriptase inhibitor; Pl, protease inhibitor

${ }^{\mathrm{a}}$ Patients can present more than one HIV transmission route

using CKD-EPI as reference and then using MDRD as reference measure. When considering only patients with eGFR $\geq 60 \mathrm{~mL} / \mathrm{min} / 1.73 \mathrm{~m}^{2}$ and CKD-EPI estimation as reference, baseline mean eGFR was $95.12 \mathrm{~mL} / \mathrm{min} /$ $1.73 \mathrm{~m}^{2}$ and $92.99 \mathrm{~mL} / \mathrm{min} / 1.73 \mathrm{~m}^{2}$ by CKD-EPI and MDRD equations, respectively $(p<0.001)$. When using the MDRD estimation as reference, baseline mean eGFR was $95.21 \mathrm{~mL} / \mathrm{min} / 1.73 \mathrm{~m}^{2}$ and $93.11 \mathrm{~mL} / \mathrm{min} / 1.73 \mathrm{~m}^{2}$ by CKD-EPI and MDRD creatinine equations, respectively $(p<0.001)$. When considering only patients with eGFR
$<60 \mathrm{~mL} / \mathrm{min} / 1.73 \mathrm{~m}^{2}$ and CKD-EPI estimation as reference, baseline mean eGFR was $48.08 \mathrm{~mL} / \mathrm{min} / 1.73 \mathrm{~m}^{2}$ and $48.60 \mathrm{~mL} / \mathrm{min} / 1.73 \mathrm{~m}^{2}$ by CKD-EPI and MDRD equations, respectively $(p=0.999)$. When using MDRD estimation as reference, baseline mean eGFR was $48.79 \mathrm{~mL} / \mathrm{min} /$ $1.73 \mathrm{~m}^{2}$ and $48.83 \mathrm{~mL} / \mathrm{min} / 1.73 \mathrm{~m}^{2}$ by CKD-EPI and MDRD equations, respectively ( $p=0.999)$.

Using the two consecutive measures of serum creatinine, the classification of patients for stages of CKD is presented in Table 2. When using the CKD-EPI formula as reference, $1091(24.2 \%)$ patients presented mild reduced GFR, $118(2.6 \%)$ patients had stage 3 CKD, and 5 $(0.11 \%)$ patients presented stage 4 CKD. When using the MDRD formula as reference, 1396 (31\%) patients presented mild reduced GFR, 116 (2.6\%) patients had stage 3 CKD, and $2(0.04 \%)$ patients presented stage 4 CKD. There were 19 patients under renal substitutive therapy at baseline (11 on dialysis and 8 kidney transplant recipients), classified as stage 5 CKD. However, the MDRD equation has not been validated for normal GFR, and is it not possible to discriminate between GFR $>90 \mathrm{~mL} /$ $\min / 1.73 \mathrm{~m}^{2}$ and between 60 and $89 \mathrm{~mL} / \mathrm{min} / 1.73 \mathrm{~m}^{2}$; they should be reported as " $\geq 60 \mathrm{~mL} / \mathrm{min} / 1.73 \mathrm{~m}$ ". On the contrary, CKD-EPI can report these two stages separately.

\section{CKD-EPI versus MDRD equations}

A substantial agreement was found between the MDRD and CKD-EPI creatinine formulae. When evaluating the absolute measures of eGRF, there was a similar distribution both in the baseline measure $(p=0.548)$ and in the second measure $(p=0.259)$.

Figure 1 shows a Bland-Altman plot of the agreement between the MDRD and CKD-EPI equations for the baseline measure and second measure of creatinine. Overall, the mean (SD) difference between the estimates from the two formulae was 2.003, with limits of agreement of 16.753 to -12.753 for the baseline measure, and 0.8232 , with limits of agreement of 17.636 to -15.9896 , for the second measure of creatinine.

Of the 4503 measurements, 4109 (91.2\%) agreed, that is, they were classified as normal, mildly decreased, moderately decreased (stage 3 ), severely decreased (stage 4) or end-stage renal insufficiency (stage 5) with both formulae, with a kappa index of 0.803 . However, $7.3 \%$ of patients were classified as having "mild renal impairment" with the MDRD equation but as having "normal renal function" with the CKD-EPI equation.

\section{Discussion}

In this large sample of HIV-infected patients, there was a good correlation between the CKD-EPI and MDRD equations. The CKD-EPI equation gave somewhat higher eGFR estimates than the MDRD formula $(95.2 \mathrm{~mL} / \mathrm{min} /$ 
Table 2 Grades of renal impairment according the National Kidney Foundation guidelines. Comparison of classifications provided using CKD-EPI and MDRD equations ${ }^{\mathrm{a}}$. Absolute frequencies (A) and percentages (B) of the studied population

(A)

\begin{tabular}{|c|c|c|c|c|c|c|c|}
\hline $\mathrm{N}$ & & $\geq 90$ & $89-60$ & $30-59$ & $29-15$ & $<15$ & Total \\
\hline \multirow[t]{5}{*}{ eGFR CKD-EPI } & $\geq 90$ & 2940 & 330 & 0 & 0 & 0 & 3270 \\
\hline & $89-60$ & 30 & 1048 & 13 & 0 & 0 & 1091 \\
\hline & $30-59$ & 0 & 18 & 100 & 0 & 0 & 118 \\
\hline & $29-15$ & 0 & 0 & 3 & 2 & 0 & 5 \\
\hline & $<15$ & 0 & 0 & 0 & 0 & 19 & 19 \\
\hline Total & & 2970 & 1396 & 116 & 2 & 19 & 4503 \\
\hline (B) & & \multicolumn{6}{|c|}{ eGFR MDRD } \\
\hline$\%$ & & $\geq 90$ & $89-60$ & $30-59$ & $29-15$ & $<15$ & Total \\
\hline \multirow[t]{5}{*}{ eGFR CKD-EPI } & $\geq 90$ & 65.3 & 7.3 & 0 & 0 & 0 & 72.6 \\
\hline & $89-60$ & 0.7 & 23.3 & 0.3 & 0 & 0 & 24.3 \\
\hline & $30-59$ & 0 & 0.4 & 2.2 & 0 & 0 & 2.6 \\
\hline & $29-15$ & 0 & 0 & 0.06 & 0.04 & 0 & 0.1 \\
\hline & $<15$ & 0 & 0 & 0 & 0 & 0.4 & 0.4 \\
\hline Total & & 66.0 & 31.0 & 2.56 & 0.04 & 0.4 & 100 \\
\hline
\end{tabular}

${ }^{\text {a }}$ Shaded cells indicate agreement between CKD-EPI and MDRD-derived eGFR estimations

$1.73 \mathrm{~m}^{2}$ and $90.4 \mathrm{~mL} / \mathrm{min} / 1.73 \mathrm{~m}^{2}$ by CKD-EPI and MDRD creatinine equations, respectively; $p<0.001$ ), resulting in smaller but non-significant numbers of patients with eGFR $<90 \mathrm{~mL} / \mathrm{min} / 1.73 \mathrm{~m}^{2}(27.4 \%$ vs. $34 \%)$. Although the clinical relevance of the difference found should be interpreted with caution, our data are consistent with observations in the general $[19,20]$ and HIV-infected populations [21], suggesting that MDRD may overestimate the severity of renal impairment. Studies in the general population comparing CKD-EPI and
MDRD against isotopic GFR observed less bias, improved precision and greater accuracy with CKD-EPI [22], although others have found lesser mean bias with MDRD [23].

In this analysis, at least a quarter of patients were diagnosed with mild reduced GFR disease (eGFR 60$89 \mathrm{~mL} / \mathrm{min} / 1.73 \mathrm{~m}^{2}$ ). This is important in detecting subclinical renal disease and identifying those patients with a higher cardiovascular risk or at risk of developing declining renal function. In practical terms, detecting 

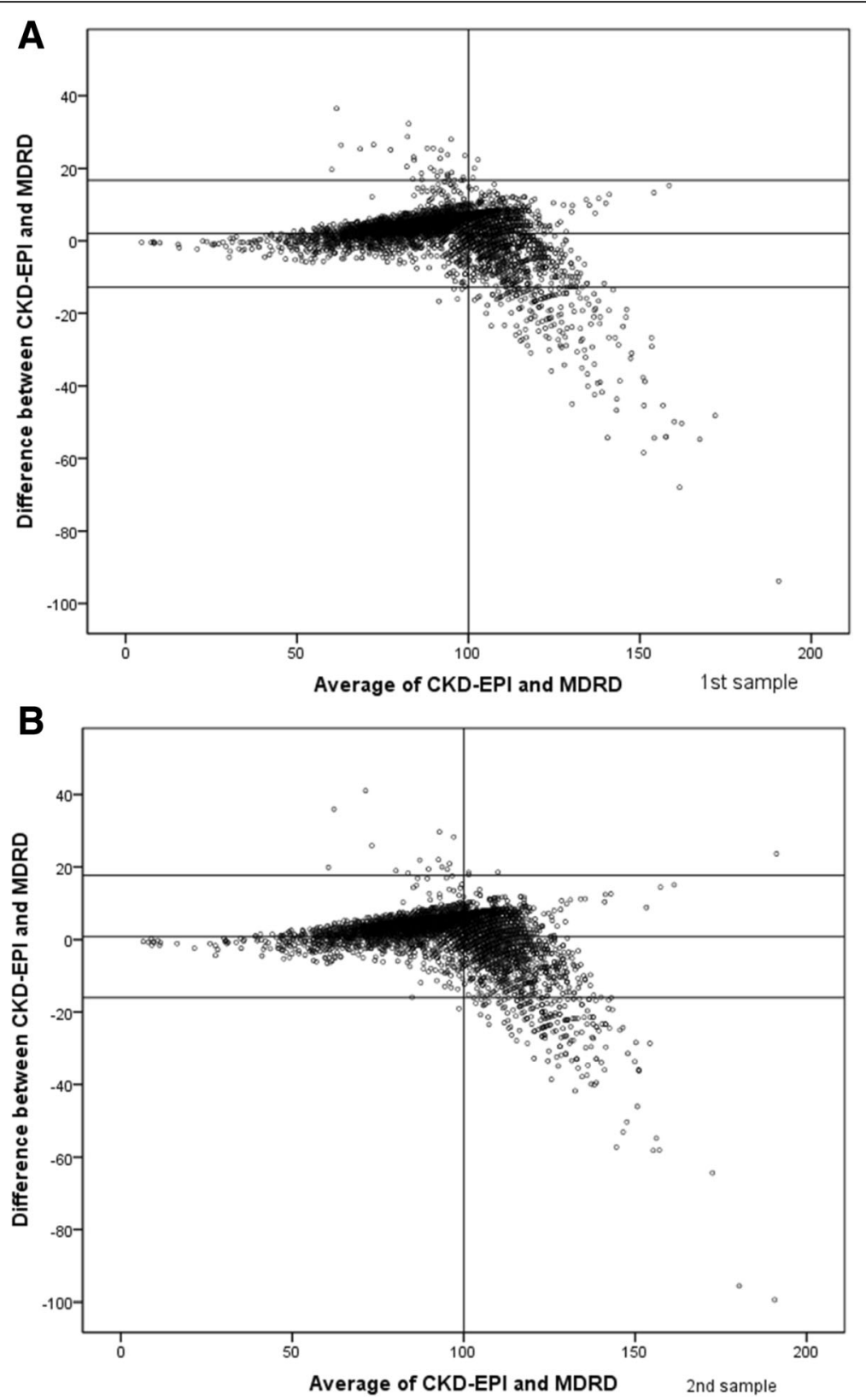

Fig. 1 Bland Altman plot of agreement between MDRD and CKD-EPI equations for baseline measure (a) and second measure of creatinine (b)

minor changes in eGFR allows the early adoption of lifestyle modification and medication therapies, as appropriate, to control hypertension, dyslipidemia and hyperglycemia. In addition, nephrotoxic medications should be avoided, and medication doses (particularly when prescribing ARV) must be adjusted for renal function. For example, Stribild ${ }^{\bullet}$ (combination of emtricitabine, tenofovir disoproxil fumarate, cobicistat and elvitegravir for a complete 1-pill, once-a-day HIV-1 treatment) prescription information contraindicates the use of this drug in patients with eGFR below $70 \mathrm{~mL} / \mathrm{min} / 1.73 \mathrm{~m}^{2}$ [24].
The MDRD equation misdiagnosed patients with apparent 'normal' renal function (over $60 \mathrm{~mL} / \mathrm{min} / 1.73 \mathrm{~m}^{2}$ ).

Chronic kidney disease stages III-V (eGFR $<60 \mathrm{~mL} /$ $\mathrm{min} / 1.73 \mathrm{~m} 2$ ) were found in $3 \%$ of HIV-infected patients with both equations, a prevalence similar to the EuroSIDA study and the French $[25,26]$ cohorts. However, this prevalence was lower than that found in a recent American analysis, in which $7.5 \%$ of HIV-infected patients had CKD [27], and even lower than a Nigerian analysis [28] that showed $52.6 \%$ of patients with GFR $<60 \mathrm{~mL} / \mathrm{min}$. Possible explanations are the higher 
proportions of blacks and hypertensive patients on American and Nigerian cohorts, the duration of untreated HIV infection, the length of exposure to nephrotoxic antiretrovirals, as well as lifestyle-related variables and socioeconomic factors reported to impact health care coverage [29].

This study has some limitations: first, its retrospective nature; second, the absence of a direct measure of glomerular filtration rate for comparison; third, the unavailability of urine protein/creatinine ratios; and, finally the absence of an outcome measure for those patients with a reduced eGFR, which fell outside the scope of this study.

In summary, the evaluation of renal function is essential for the clinical management of patients with HIVinfection. In line with observations in the general population, this study suggests that the MDRD equation may underestimate renal function in subjects with GFRs over $60 \mathrm{~mL} / \mathrm{min} / 1.73 \mathrm{~m}^{2}$. The main contribution of this report was that the CKD-EPI equation identified $24 \%$ of patients with mild reduced eGFR, not identified using the MDRD equation. This finding has strong implications for clinical practice, as it provides a framework for identifying patients at risk of poorer outcomes (overt chronic kidney disease, cardiovascular disease and mortality) and allows better clinical management, especially in terms of the dose adjustment of antiretroviral drugs.

\section{Conclusion}

In conclusion, the CKD-EPI equation must be considered as the first-choice method to evaluate renal function in patients with HIV-infection.

\section{Abbreviations}

ARV: Antiretroviral therapy; CG: Cockroft-gault; CKD: Chronic kidney disease; CKD-EPI: CKD epidemiology collaboration; eGFR: Estimated glomerular filtration rate; GFR: Glomerular filtration rate; HIV: Human immunodeficiency virus; IQR: Interquartile range; K/DOQI: US national kidney foundation's kidney disease outcome quality initiative; MDRD: Modification of diet in renal disease; NKF: National kidney foundation; SD: Standard deviation

\section{Acknowledgements}

To the patients.

CKD-H. Clinic Investigators

Fritz Dieckman, Nephrology and Renal Transplantation Service, Hospital Clinic IDIBAPS; Aleix Cases, Nephrology and Renal Transplantation Service, Hospital Clinic - IDIBAPS; Esteban Poch, Nephrology and Renal Transplantation Service, Hospital Clinic - IDIBAPS; Esteban Martinez, Infectious Diseases Service, Hospital Clinic - IDIBAPS; José Luís Blanco, Infectious Diseases Service, Hospital Clinic IDIBAPS; Felipe García, Infectious Diseases Service, Hospital Clinic - IDIBAPS; Josep Mallolas, Infectious Diseases Service, Hospital Clinic - IDIBAPS; Josep María Gatell, Infectious Diseases Service, Hospital Clinic - IDIBAPS.

\section{Funding}

This work was supported in part by Red de Sida RD12/0017/0001. JMM received a personal intensification research grant \#INT15/00168 during 2016 from Instituto de Salud Carlos III, Madrid, Spain. The European Regional Development Fund (ERDF) "A way to build Europe" also provided funding.

\section{Availability of data and materials}

All the datasets during and/or analyzed during the current study are available from the corresponding author on reasonable request.

\section{Authors' contributions}

MPC, FC: study design, data acquisition, statistical analysis, data interpretation, intellectual contributions, revision and approval of manuscript. NR, JCT, CM, FA, $J L B, A M, F O$ : data acquisition, data interpretation, intellectual contributions, revision and approval of manuscript. JMM: study design, data acquisition, data interpretation, intellectual contributions, revision and approval of manuscript.

\section{Competing interests}

The authors declare that they have no competing interests.

\section{Consent for publication}

Not applicable once do not include details, images, or videos relating to individual participants.

\section{Ethics approval and consent to participate}

The study was performed in accordance with the Declaration of Helsinki, and the study project was reviewed and approved by the Hospital Clinic Institutional Review Board (\#HCB/2014/1080). All data were anonymized to comply with the provisions of personal data protection legislation. Due to the retrospective nature of this study and due the fact that only historical medical data were collected, written informed consent was not required.

\section{Author details}

${ }^{1}$ Kidney Transplant Division, Hospital do Rim (São Paulo, Brazil), Universidade Federal de São Paulo, São Paulo, Brazil. ${ }^{2}$ Nephrology and Renal

Transplantation Service, Hospital Clinic - IDIBAPS, University of Barcelona, Barcelona, Spain. ${ }^{3}$ Core Laboratory, Biomedical Diagnosis Centre, Hospital Clínic, Barcelona, Spain. ${ }^{4}$ Internal Medicine Service, Hospital de Olot, Girona, Spain. ${ }^{5}$ Medical Sciences Department, University of Girona, Girona, Spain. ${ }^{6}$ Infectious Diseases Service, Hospital Clinic - IDIBAPS, University of Barcelona, Barcelona, Spain.

Received: 18 July 2016 Accepted: 31 January 2017

Published online: 10 February 2017

\section{References}

1. Deeks SG, Lewin SR, Havlir DV. The end of AIDS: HIV infection as a chronic disease. Lancet. 2013;382(9903):1525-33.

2. Mocroft A, Brettle R, Kirk O, Blaxhult A, Parkin JM, Antunes F, Francioli P, D'Arminio Monforte A, Fox Z, Lundgren JD, e group., EuroSIDA study. Changes in the cause of death among HIV positive subjects across Europe: results from the EuroSIDA study. AIDS. 2002;16(12):1663-71.

3. Miro JM, Cofan F, Trullas JC, Manzardo C, Cervera C, Tuset M, Oppenheimer F, Brunet M, Moreno A, Campistol JM, Gatell JM. Renal dysfunction in the setting of HIV/AIDS. Curr HIV/AIDS Rep. 2012;9(3):187-99.

4. Mocroft A, Kirk O, Reiss P, De Wit S, Sedlacek D, Beniowski M, Gatell J, Phillips AN, Ledergerber B, Lundgren JD, e Group., EuroSIDA Study. Estimated glomerular filtration rate, chronic kidney disease and antiretroviral drug use in HIV-positive patients. AIDS. 2010;24(11):1667-78.

5. Fernando SK, Finkelstein FO, Moore BA, Weissman S. Prevalence of chronic kidney disease in an urban HIV infected population. Am J Med Sci. 2008; 335(2):89-94.

6. Lucas GM, Clarke W, Kagaayi J, Atta MG, Fine DM, Laeyendecker O, Serwadda D, Chen M, Wawer MJ, Gray RH. Decreased kidney function in a community-based cohort of HIV-Infected and HIV-negative individuals in Rakai, Uganda. J Acquir Immune Defic Syndr. 2010;55(4):491-4.

7. Sorlí ML, Guelar A, Montero M, González A, Rodriguez E, Knobel H. Chronic kidney disease prevalence and risk factors among HIV-infected patients. J Acquir Immune Defic Syndr. 2008;48(4):506-8.

8. Odongo P, Wanyama R, Obol JH, Apiyo P, Byakika-Kibwika P. Impaired renal function and associated risk factors in newly diagnosed HIV-infected adults in Gulu Hospital, Northern Uganda. BMC Nephrol. 2015;16:43.

9. Lucas GM, Mehta SH, Atta MG, Kirk GD, Galai N, Vlahov D, Moore RD. Endstage renal disease and chronic kidney disease in a cohort of AfricanAmerican HIV-infected and at-risk HIV-seronegative participants followed between 1988 and 2004. AIDS. 2007;21(18):2435-43. 
10. Ryom L, Mocroft A, Lundgren J. HIV therapies and the kidney: some good, some not so good? Curr HIV/AIDS Rep. 2012;9(2):111-20.

11. Soveri I, Berg UB, Björk J, Elinder CG, Grubb A, Mejare I, Sterner G, Bäck SE, SBU GFR Review Group. Measuring GFR: a systematic review. Am J Kidney Dis. 2014;64(3):411-24.

12. Delanaye P, Mariat $C$. The applicability of eGFR equations to different populations. Nat Rev Nephrol. 2013;9(9):513-22.

13. Gagneux-Brunon A, Delanaye P, Maillard N, Fresard A, Basset T, Alamartine E, Lucht F, Pottel H, Mariat C. Performance of creatinine and cystatin C-based glomerular filtration rate estimating equations in a European HIV-positive cohort. AIDS. 2013;27(10):1573-81.

14. Inker LA, Wyatt C, Creamer R, Hellinger J, Hotta M, Leppo M, Levey AS, Okparavero A, Graham H, Savage K, Schmid CH, Tighiouart H, Wallach F, Krishnasami Z. Performance of creatinine and cystatin C GFR estimating equations in an HIV-positive population on antiretrovirals. J Acquir Immune Defic Syndr. 2012;61(3):302-9.

15. Lucas GM, Ross MJ, Stock PG, Shlipak MG, Wyatt CM, Gupta SK, Atta MG, Wools-Kaloustian KK, Pham PA, Bruggeman LA, Lennox JL, Ray PE, Kalayjian RC. Clinical Practice Guideline for the Management of Chronic Kidney Disease in Patients Infected With HIV: 2014 Update by the HIV Medicine Association of the Infectious Diseases Society of America. Clin Infect Dis. 2014 Sep 17. [Epub ahead of print].

16. AIDS Working Group (GESIDA) of the Spanish Society of Infectious Diseases and Clinical Microbiology (SEIMC); Spanish Society of Nephrology (S.E.N.); Spanish Society of Clinical Chemistry and Molecular Pathology (SEQC). Consensus document on the management of renal disease in HIV-infected patients. Nefrologia. 2014;34 Suppl 2:1-81.

17 Delanaye P, Mariat C, Maillard N, Krzesinski JM, Cavalier E. Are the creatininebased equations accurate to estimate glomerular filtration rate in African American populations? Clin J Am Soc Nephrol. 2011;6(4):906-12.

18 Group., Kidney Disease: Improving Global Outcomes (KDIGO) Chronic Kidney Disease Work. KDIGO 2012 clinical practice guideline for the evaluation and management of chronic kidney disease. Kidney Int Suppl. 2013;3:150.

19 Sánchez-Chaparro MA, Calvo-Bonacho E, González-Quintela A, Cabrera M, Quevedo-Aguado L, Fernández-Labandera C, Ruiz-Moraga M, Sainz-Gutiérrez JC, Gómez-Martínez P, Román-García J, Felices PV, Ruilope LM, Zanchetti A et al. Estimating the glomerular filtration rate in the Spanish working population: chronic kidney disease prevalence and its association with risk factors. J Hypertens. 2014;32(10):1970-8.

20 Michels WM, Grootendorst DC, Verduijn M, Elliott EG, Dekker FW, Krediet RT. Performance of the Cockcroft-Gault, MDRD, and new CKD-EPI formulas in relation to GFR, age, and body size. Clin J Am Soc Nephrol. 2010;5(6):1003-9.

21 Ibrahim F, Hamzah L, Jones R, Nitsch D, Sabin C, Post FA e Group., UK CHIC/CKD* Study. Comparison of CKD-EPI and MDRD to estimate baseline renal function in HIV-positive patients. Nephrol Dial Transplant. 2012;27(6):2291-7.

22 Levey AS, Stevens LA, Schmid CH, Zhang YL, Castro 3rd AF, Feldman HI, Kusek JW, Eggers P, Van Lente F, Greene T, Coresh J, e Collaboration, CKDEPI (Chronic Kidney Disease Epidemiology). A new equation to estimate glomerular filtration rate. Ann Intern Med. 2009;150(9):604-12.

23 Levey AS, Coresh J, Greene T, Marsh J, Stevens LA, Kusek JW, Van Lente F, e Collaboration., Chronic Kidney Disease Epidemiology. Expressing the modification of diet in renal disease study equation for estimating glomerular filtration rate with standardized serum creatinine values. Clin Chem. 2007;53(4):766-72.

24 Gilead Sciences Inc.Stribild (elvitegravir/cobicistat/tenofovir/emtricitabine) [package insert] Foster City, CA: 2012.

25 Mocroft A, Kirk O, Gatell J, Reiss P, Gargalianos P, Zilmer K, Beniowski M, Viard JP, Staszewski S, Lundgren JD. Chronic renal failure among HIV-1-infected patients. AIDS. 2007;21(9):1119-27.

26 Flandre P, Pugliese P, Cuzin L, Bagnis CI, Tack I, Cabié A, Poizot-Martin I, Katlama C, Brunet-François C, Yazdanpanah Y, Dellamonica P, e group. - New AIDS Data. Risk factors of chronic kidney disease in HIV-infected patients. Clin J Am Soc Nephrol. 2011;6(7):1700-7.

27 Overton ET, Nurutdinova D, Freeman J, Seyfried W, Mondy KE. Factors associated with renal dysfunction within an urban HIV-infected cohort in the era of highly active antiretroviral therapy. HIV Med. 2009;10(6):343-50.
28 Emem CP, Arogundade F, Sanusi A, Adelusola K, Wokoma F, Akinsola A. Renal disease in HIV-seropositive patients in Nigeria: an assessment of prevalence, clinical features and risk factors. Nephrol Dial Transplant. 2008; 23(2):741-6.

29 Evans K, Coresh J, Bash LD, Gary-Webb T, Köttgen A, Carson K, Boulware LE. Race differences in access to health care and disparities in incident chronic kidney disease in the US. Nephrol Dial Transplant. 2011;26(3):899-908.

\section{Submit your next manuscript to BioMed Central and we will help you at every step:}

- We accept pre-submission inquiries

- Our selector tool helps you to find the most relevant journal

- We provide round the clock customer support

- Convenient online submission

- Thorough peer review

- Inclusion in PubMed and all major indexing services

- Maximum visibility for your research

Submit your manuscript at www.biomedcentral.com/submit

) Biomed Central 